\title{
Designing a Model of Micro Factor Affecting Personal Brand Development for Professional Athletes with Grounded Theory Approach
}

\author{
${ }^{1}$ Mehdi Nazemi, ${ }^{2}$ Seyed Morteza Azimzadeh*, ${ }^{3}$ Mahdi Talebpour, ${ }^{4} \mathrm{D}$. Todd Donovan \\ ${ }^{1}$ Department of Sport Management, Faculty of Sport Science, Ferdowsi University of Mashhad, Mashhad, \\ Iran. ${ }^{2}$ College of Business, Colorado State University, Colorado, USA.
}

Submitted 19 January 2020; Accepted in final form 07 April 2020.

\begin{abstract}
Background. As a component of the sports industry, professional athletes are always faced with challenges, including injury, performance loss, etc. To overcome these problems, many famous athletes have turned to build their brands, as it enables them to create and maintain a market of customers and fans. Objectives. The purpose of this study was to use the Grounded theory approach to design a model of the micro factor affecting personal brand development for Professional athletes. Methods. The present study was an applied research with a descriptive-survey method, and a library-field data collection method. This research was a qualitative research and was carried out using the Grounded Theory method. In the present study, semi-structured interviews were used as data gathering tools. Sampling was done using judgmental sampling method and followed up to theoretical saturation, which included a total of 18 interviewees. Results. Based on the findings, after three stages of open coding, selective coding, and theoretical coding, a total of 62 concepts, 11 categories, and 4 factors were obtained that showed "Athlete's Behaviors", "Athlete's Personality Traits", "Marketable Lifestyle" and "Athletic Performance" play an important role in developing the personal brand for professional athletes. Conclusion. By identifying the factors affecting the personal brand of professional athletes, athletes, managers, and marketers can create and maintain a market for their customers and fans, achieve sustainable income and maintain reputation and popularity.
\end{abstract}

KEYWORDS: Personal Brand, Professional Athletes, Athlete's Behaviors, Marketable Lifestyle, Athlete's Personality Traits.

\section{INTRODUCTION}

Before going to the definition of personal branding, it is important to understand the meaning of a brand. Miletsky and Smith $(2009,2)$ define a brand as "the sum total of all user experiences with a particular product or service, building both reputation and future expectations of benefit." This definition states quite clearly the true nature of a brand. The brand aims is to build a bridge between the company and its consumers and, as a consequence, create mutually beneficial long-term relationships (1). A brand or trade name is: a name, a term, a mark, a sign, a symbol, a layout or a combination of those used to identify a seller's products or services or a group of sellers and to distinguish them from competitor's products. The brand is the seller's permanent commitment to offering the customers a set of specific features, benefits and services (2). In the new era, branding is no longer just for companies, and today a new trend has emerged as personal

*. Corresponding Author:

Seyed Morteza Azimzadeh, Assistant Professor

E-mail: mortezaazimzade@um.ac.ir 
marketing (3). The concept of the brand today is much more generalized than its source and is not limited to services and goods, but a new phenomenon has emerged called personal branding. The brand is now rapidly being applied in various cultural, social, political and even virtual domains (4).

A personal brand is a combination of all the expectations, images and perceptions around a character. That is, when others see or hear that person's name, those images and perceptions come to their mind (4). In the political space of the age of media-influenced individualism, Manuel Castells, being a professional or brand celebrity, is considered to be an essential asset in the age of individualism, virtual and online (5). This is becoming increasingly important and has become the key to success in life. This strategy has been behind the lives of today's most successful athletes like Tiger Woods, Michael Jordan and Cristiano Ronaldo.

Defining an athlete brand is a fundamental step in the process of model development. Several scholars have attempted to define "human brand", but a common consensus has not yet been achieved. A brand in sports is defined as "a name, design, symbol, or any combination that a sports organization uses to help differentiate its product from the competition" (6). According to this definition, all individual athletes can be considered as brands because every athlete has a name, distinctive appearance, and a personality. Consistent with this, Thomson (2006) broadly defined the human brand as "any well-known persona who is the subject of marketing communications efforts" (7). The other hand, according to Keller (2008), "A brand is something that has actually created a certain amount of awareness, reputation, prominence, and so on in the market place" (8). Till (2001) discussed athlete brand in a limited sense, and implied that only athletes who have earned a significant amount of money from endorsement contracts can be considered as brands. By applying these basic concepts, we define an athlete brand as a public persona of an individual athlete who has established their symbolic meaning and value using their name, face or other brand elements in the market (9). Personal branding works in the same way as any other form of branding, the only difference being that personal branding is about branding a person, hovewer it still has similar benefits. Montoya (2002) states that personal branding is "A personal identity that stimulates precise, meaningful perceptions in its audience about the values and qualities that person stands for". In other words, personal branding enables one to promote their message and share the values and character behind the person to the audience (10).

There are numerous advantages in personal branding that can be achieved with a strong personal brand. Personal branding boosts potential value as it increases visibility and gives actions more weight. It attracts the right people and enables opportunities as when someone is looking for a potential candidate, by having a personal brand one can be recalled and considered more effective. Through personal branding, a person obtains recognition and as a consequence gets credit and opportunities. Therefore it is possible to conclude that having a personal brand increases one's visibility, recognition and most of all value. (10). So what is important for professional athletes is what factors affect their brands and how can they develop them.

Given that the main role of athletes is showing sport performance, their athletic success affects their brand (11). Xiaohua \& Songling (2010) found that various factors, such as job stability and the team in which the athlete is a member, influence the personal brand of the athletes. The status of sports heroes has a significant impact on their brand image, but at the same time, the performance of the athlete alone can act as a risk factor (12). According to Braunstein \& Zhang (2005), the athlete's ability to perform sports is one of the most important factors in building a target market for the athlete (13). Sassenberg et al. (2012) presenting the conceptual model of the brand image of sports celebrities stated that sport skill levels, validity, reliability, attractiveness and personality traits are among the influential factors on brand image of sports celebrities. Also, the brand image of sports celebrities can be an effective factor in marketing communications (14).

Cortsen (2013) states that social responsibility may help build a positive brand image. In the age of media and communications, where media culture is wholly and rapidly and completely 
reflecting what is happening, a player's off-field recklessness can play a vital role in understanding the athletes' personal story. Therefore, given that sports brands are often based on the values and qualities of sports heroes, consumers are more attracted to them (15). Arai et al. (2013) classify factors affecting athletes brand image into two general categories of on-field and off-field characteristics. In the same vein, the athlete's performance is described as on-field features and the appeal of appearance and lifestyle as the offfield features of the brand image (16).

Gander (2014) states that you need to work hard to develop your personal brand, learn new skills, have penetrating story, rebuild old communication, start new method, use social media and create content for yourself (17). Green (2016) stated that social networks with dimensions such as personality, endorse, exposure, creative, response, follow and target audience effect on the personal brand of professional athletes (18). Hasaan (2016), in a research aimed to study the opinion of Pakistani fans about the brand of foreign cricket athlete in the Pakistani Super League, stated that the athlete's brand components with on-field characteristics (behavior, team, achievements, playing style and skills) and off-field characteristics (Physical attraction, lifestyle, personal demand, ethnicity and entertainment) are related. Also, the athlete's brand in the field of loyalty to the athlete (media, creating their own narratives, positive advice advertising, resisting change and commitment), loyalty to the sports team (team replacement, supporting multiple teams and generating revenue) and loyalty to Athlete sponsors are effective (19).

Figurska (2016) cited affability, self-esteem, accuracy, diligence, honesty, conscientiousness and creativity as the most important individual traits in individuals with strong personal branding (20). Rangarajan et al. (2017) concluded that unlike companies or products, individuals has internalized personal branding as a result of their personality quality, past experiences, and relationships with others, meaning that every person already has a personal brand of a certain kind (21). Erdoğmuş and Esen (2018) presented a model for making executive's personal brand in which factors such as Family Background, Social Capital, Developmental work experience, Career motivation, Management philosophy and approach, Change management, Challenging experiences, Stakeholder relations, Selfpresentation and Firm performance were mentioned (22). In the study of Hassan et al. (2019), with the aim of providing a framework to help understand the athlete's brand life cycle and how to proceed, five steps were identified including brand introduction, brand growth, brand maturity, brand decline and brand reinvention and how to develop and manage The lifecycle of the athlete's brand was determined during his career (23).

Dumont and Oates (2020) in their research, stated that personal branding is a rapidly growing phenomenon taking place in multistakeholder ecosystems. This article builds on ethnographic fieldwork from the rock-climbing industry in the US and Europe to show how stakeholders enable and shape the personal branding practices of professional climbers. Findings demonstrate that personal branding is a highly social practice wherein stakeholders provide three types of resources to elaborate personal brands: material resources, informational resources, and symbolic resources. In addition, six main conventions guiding stakeholders' relationships and enabling resource transfer are then identified and theorized. Finally, these findings are built upon to suggest a framework to analyze stakeholder cooperation in personal Branding (24).

In recent years, with the recognition of the importance of branding for various industries, the sports industry has also adopted the use of branding techniques to achieve its goals. As a part of the sports industry, professional athletes are always faced with challenges, including injury, loss of performance, and end of training course. What can help athletes face these challenges is a strong image in the minds of fans. As the main purpose of branding is to differentiate products and services, personal branding is also a form of competition to gain more acceptance and influence over customers and seek to create a strong and desirable image for greater profitability. Customers, on the other hand, tend to look for features that distinguish their favourite athlete from other competitors. Many famous athletes have turned to build their own brands because personal branding can create and 
maintain a market of their customers and fans that the results of this study can guide professional athletes to build their own brand.

Despite the importance of personal branding for athletes, with the exploration of the database of scientific and research resources, no comprehensive and coherent study has yet been conducted on the factors affecting the development of personal branding in sports. The lack of attention to personal branding among athletes seems to be affected by the lack of research into personal branding. However, for personal branding, the first and foremost measure of designing a model is related to the micro factors influencing personal brand development. Therefore, considering the importance of the subject and the gap in the research about personal brand and its influential components in sport, this study aimed to comprehensively review the background and views of authors and researchers working in the field of personal brand designed and explained personal brand development so that we can achieve the expected competencies of professional athletes through the functions and consequences thereof. The proposed model helps professional athletes to consider the factors influencing their personal brand and move on to develop their own brand and achieve lasting reputation and revenue.

\section{MATERIALS AND METHODS}

The main object of the present study was to design a model for the development of professional athletes' personal brand. The present study was conducted in the framework of a qualitative approach using the Grounded theory approach. Given that Grounded theory fits the position of this research and represents a good and appropriate explanation of existing theories, this method was chosen. The Grounded theory consists of three approaches: the systematic approach known as Strauss and Corbin (1990), The Emergent approach proposed by Glaser (1992) and the Constructivist approach proposed by Charmaz (2006). Glaser (1992) believes that by imposing a systematic approach rather than allowing data to emerge, researchers impose categories on the data (25). Therefore, in this study, a Glaser approach was used. The method of data collection in this study was library study and semi-standard or semi- structured in-depth interviews with experts. The statistical population of this study consists of professors and experts in sport marketing and sport branding and international professional athletes with specialized education in sport management, because these people have good knowledge and understanding on the pivotal phenomenon of research, their comments can help the researcher identify unknown factors.

Purposeful sampling model and successive reference technique (snowball) were used for sampling. First, the individuals were directly selected by the researcher based on their judgment of the best sources of information such as written sources, observation and interviews with experts in the field, then subsequent groups were introduced for interviewing by the same individuals and sampling continued to some extent that the model reached the theoretical saturation level. In this study, the model reached the theoretical saturation level in the 15 interviews so that no further thought emerged as the interview continued, but researcher interviews with 18 individuals to ensure the results. In-depth individual interviews with each participant took between 30 and 70 minutes. According to the Glaser approach of the research, all interviewees did not answer the same questions, but the questions were asked to guide the interviews. During the interview, various methods such as noting and recording of the interview were recorded on audio or video tape. Immediately after the interview, detailed notes on the interviews were written. The ability to keep and record information from interviews is as important as gathering it, and the quality of information will be lost if the information is not collected properly.

To evaluate researches based on data-based theorizing, the acceptance has been proposed rather than validity and reliability. Acceptability means to what extent the findings of the research are credible in reflecting the experiences of the participants, the researcher, and the reader about the phenomenon under study. Ten indicators have been introduced for acceptance standard, 5 of which were used in this study to improve scientific accuracy, validity and reliability. The audit strategies used were researcher sensitivity, methodological consistency, sample fit, replication of a finding, and use the feedback of 
the informed (26). In the process of analyzing the data-based theory, the interview and textual data are coded in a Glaser way. The coding of information consists of two stages and three steps: actual coding (open coding, selective coding) and theoretical coding.

Open coding: After the interview, the open coding process begins. The output of the open coding stage is basic codes. Open coding can be done by line-by-line coding, phrase by phrase, or paragraph by paragraph of data. Selective Coding: When the core category in the open coding process is achieved, the selective coding process begins and the interviews are coded in the pivotal variable. Selected coding deals with coding for the pivotal variable, that is, the process of converting concepts into categories. Theoretical coding: Theoretical coding is the process of integrating and improving categories. Theoretical codes conceptualize how categories relate to one another. Open and selective coding deals with categorizing, classifying, and actually fragmenting data, but at this stage, through theoretical codes, we relate concepts to each other.

\section{RESULTS}

In this study, using the seven-step Glaser method, the primary codes were refined after each interview and classified according to their compatibility with other discovered concepts; this method was repeated many times that after repeated refinements 62 concepts, 11 categories and 4 dimensions were identified. Initially, at the end of each interview and recording of field notes, all statements and descriptions given by the interviewee are repeatedly heard (if the interview is recorded) or read (if taken). The purpose was to gain or "understand a feeling" and the participant's experiences.

Secondly, after reading all the sentences, phrases, and descriptions of the interviewee, the following statements and phrases related to the phenomenon under discussion are underlined. This is how "important sentence extraction" takes place. In the third stage, we try to understand the meaning and notion of each important sentence. This is called "formulating meanings". In other words, the researcher tries to extract from each phrase a concept that expresses the meaning and essential part of one's thoughts. In the fourth step, after extracting these codes, the researcher carefully studies the compiled concepts and classifies them according to their similarities. It is formed by "categorizing similar concepts" (categories) such as "Athletic expertise" or "Life story".

In the fifth step, in addition to extracting important sentences and classifying subjects, all the extracted concepts are carefully studied and linked together according to their similarities, and more general categories are formed called dimensions. By "categorizing similar categories", dimensions such as "Athletic performance" or "lifestyle" are formed. In the sixth stage, all the extracted dimensions are linked together into a "comprehensive description of the phenomenon under study (personal brand of professional athletes)" and a broader category emerged. In the seventh stage, participants can be inquired their opinions about the findings by referring back to each participant and conducting a single interview or conducting multiple interview sessions and take steps toward ultimate validity test of findings (27). Table 1 shows the details of the interviewees. According to the table we can assure the suitability of the research samples.

Table 1. Details of Interview Participants

\begin{tabular}{lc}
\hline \multicolumn{1}{c}{ Gender } & Values \\
Female & \\
Male & 2 \\
Education Level & 16 \\
PhD & 13 \\
PhD Student & 5 \\
Field & 17 \\
Sport Management & 1 \\
Business Administration & 18 \\
Total
\end{tabular}

In this study, the researcher repeatedly analyzed the data and initial codes, and in each analysis identified new concepts and revised them so that they could finally be categorized into topics and then categories. To be more precise, the way to get to the "basic codes" was that at the end of each interview, the sentences were pondered separately, then the main message or "key concept" hidden in each sentence was achieved. This study aimed to design a model of micro factors affecting on development of professional athletes' personal brand and, the results of professional athletes' personal brand development were identified as a pivotal phenomenon in this study. After performing three steps of open coding, selective coding and theoretical coding, a total of 62 concepts, 11 categories, and 4 dimensions were obtained as shown in Table 2. 
Table 2. Selected Codes (Concepts), Categories and Extracted Dimensions

\begin{tabular}{|c|}
\hline Concepts \\
\hline Trustworthy \\
\hline Being well-known \\
\hline Being Religious \\
\hline Courtesy \\
\hline Kindness and Humility \\
\hline Wisdom \\
\hline Individual and Team Discipline \\
\hline Authentic Identity \\
\hline Respect for the Veteran \\
\hline Legality \\
\hline Social Responsibility \\
\hline Sympathy for the Injured People \\
\hline Charitable Activities \\
\hline Entrepreneurship \\
\hline Body Fitness \\
\hline Appearance Commensurate with the Custom of Society \\
\hline Nice Appearance \\
\hline Attractive and Distinctive Personal Style \\
\hline How to Speak and Tone of Voice \\
\hline Fashionable Behavior \\
\hline Correct Endorsement \\
\hline Charisma \\
\hline Creativity \\
\hline Popularity \\
\hline Family Loyalty \\
\hline Academic Degrees \\
\hline Professional Life \\
\hline Glory to the Hometown \\
\hline Family History \\
\hline Exciting Events in Life \\
\hline Athlete's Ethnicity \\
\hline Strong Financial Backing \\
\hline Participate in Cultural and Political Activities \\
\hline Expressing Opinions \\
\hline Attending in Social Events with People \\
\hline Competent Leadership \\
\hline No Negative Glosses \\
\hline Networking \\
\hline Having Famous Sponsors \\
\hline Attention and Appreciation from Fans \\
\hline Having your own Logo and Slogan \\
\hline Having a Site \\
\hline Vision, Mission and Goals \\
\hline Using the right tools for self- presentation \\
\hline Marketing Skills \\
\hline The Number of Followers on Social Networks \\
\hline Having Famous Fans \\
\hline High Skill \\
\hline International Awards Nomination \\
\hline Notable Records \\
\hline Historical Wins \\
\hline Continuation of Success \\
\hline Attending Prestigious Leagues \\
\hline Distinct Competition Style \\
\hline Exciting Competition Style \\
\hline Serving as a Team \\
\hline Fair Play \\
\hline Patriotism \\
\hline Effort and Perseverance \\
\hline Bigotry \\
\hline Loyalty to the Club \\
\hline Respect for the Referee \\
\hline
\end{tabular}


In Figure 1, the final model of the research is presented. Based on this model, the personal brand of professional athletes is at the center of the model, and "Athlete Behaviors", "Athlete Personality Traits", "Marketable Lifestyle" and
"Athletic Performance" have important role in association with personal brand development. It is worth noting that Table 1 only refers to code titles, while the frequency of each code is different and not mentioned because of its huge details.

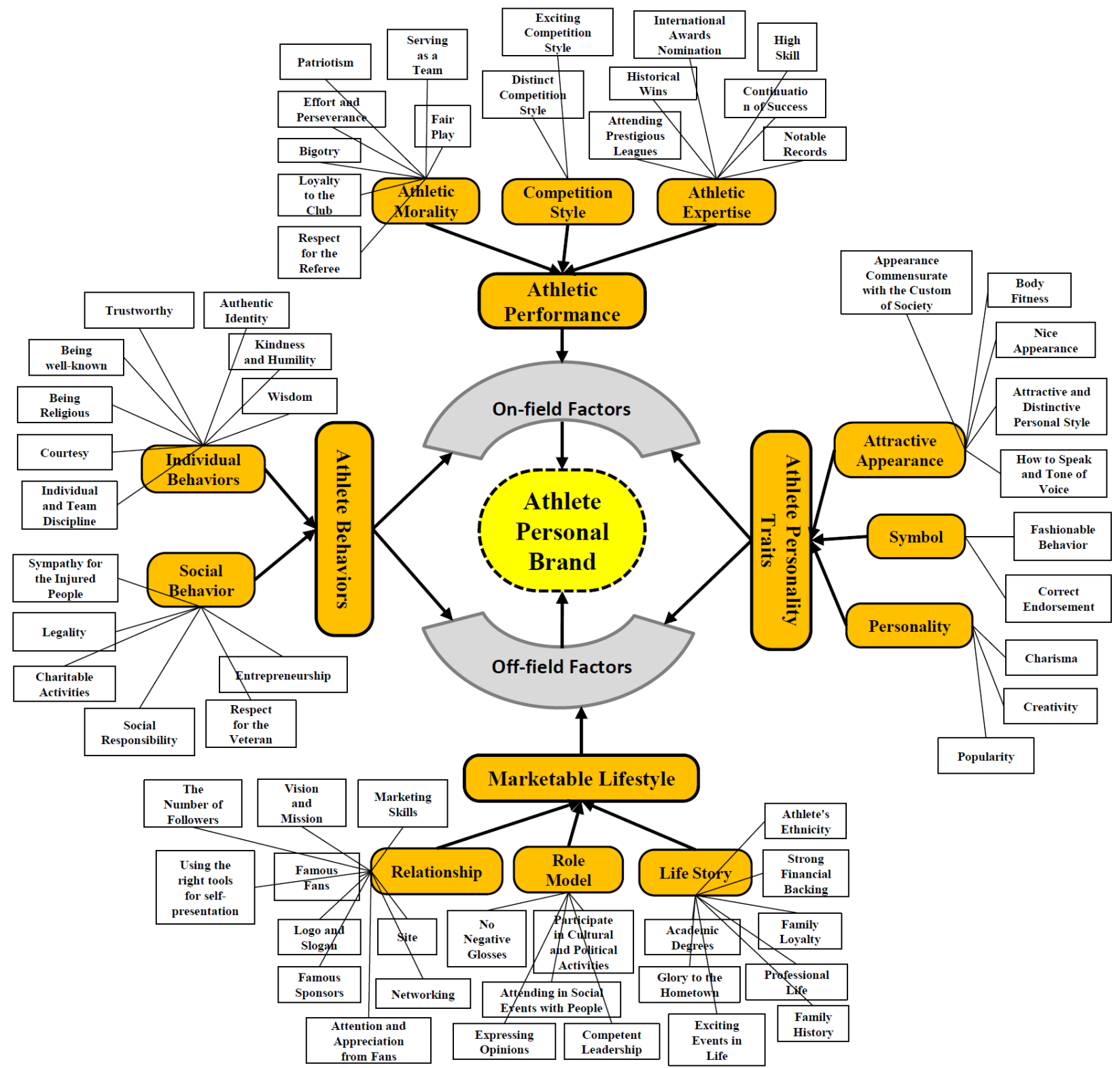

Figure 1. Model of Personal Brand of Professional Athletes

\section{DISCUSSION AND CONCLUSION}

Today in the sports industry, brand managers and agents are often responsible for managing the athlete's brand and helping athletes create opportunities to expand their brand and increase their fans. However, no research has been conducted in sport management literature on the role of different factors on professional athletes' personal brand development. If we look at the behavior of fans in sports, we find that they are a group that is overwhelmed. The color and number of their shirts is the same as their favorite team color and their favorite athlete number and even the color of their body is the same. The presence of these spectators in the stadiums and encouraging their favorite teams and athletes not only enhances the grace and excitement of the competition, but also has a great mental impact on 
the performance of the team and the athletes. In addition, income in sports is mostly dependent on major company advertising, and large corporations go to teams and athletes who have a lot of fans and many people watching their games, which ultimately leads to many people watching that company. Accordingly, team and athlete fans may be influenced by and remain loyal to the team and athlete's brand because fans play an important role in creating the team and athlete's product; In other words, fans are not just seen as customers in the sport, they are part of a unique team and athlete product.

Therefore, the present study aimed to identify the micro factors affecting the development of professional athletes' personal brand using a grounded theory approach. The data were collected using in-depth and semi-structured interviews with sports marketing and branding experts and experts and internationally trained sports management heroes who have a successful personal brand in the sports industry. In the present study, researchers reviewing existing research literature in this field, in addition to emphasizing the results of previous studies, provide new knowledge and information on personalized and applied professional development of professional athletes. Accordingly, the present study contributes to a new understanding and awareness of the phenomenon by designing a personal brand model for professional athletes and presenting the findings. Based on the results, the main research factors were identified and confirmed in 5 distinct dimensions consisting of 11 categories and 62 concepts. The results of the present study indicate that the personal branding process for professional athletes requires appropriate support and development of individual infrastructures that combine athlete personality traits and athlete behavior on and off the field that can act as an accelerator and controller and operate sustainable development, provide personal branding, and facilitate and accelerate necessary actions.

According to the results of the research, athletic performance was identified as one of the factors of personal brand development of professional athletes. This component refers to an athlete's performance in the field of sports, It has the dimensions of athletic expertise, competition style and athletic morality, so athletes can provide its conditions by pursuing fair play, bigotry, loyalty to the team and trying to continue their sporting success, forming a distinctive style of competition, adding the excitement of competitions for developing of their brand. Personality characteristics is another crucial aspect of professional athletes' personal brand development, this scale includes attractive appearance, symbol and personality. The findings of this study suggest that attractive appearance is a factor affecting the personal brand of professional athletes and is correspondent with the results of the studies by Arai et al. (2013), Hasaan et al. (2016), Hasaan (2016), Hasaan et al. (2015), and Liu et al. (2011) (19, 26, 28-30). Accordingly, athletes must pay attention to how they are covered, being up-to-date and fashionable in order to develop and expand their brand. Marketing managers, club managers, and teams should also pay attention to this and design and implement methods and strategies for using and utilizing athletes' coverage to enhance the athlete's personal brand value.

Marketable lifestyle as one of the dimensions of a professional athlete's personal brand equals the presence, behavior and activities of athlete in society and out of the field. This finding emphasizes that role model of professional athletes in social activities, favorable communication and appreciation and accountability to fans make them successful. Thus, by engaging in social, philanthropic, cultural activities, and avoiding inappropriate, immoral and abusive behaviors, athletes can enhance their marketable lifestyle and develop their own brand. These results are in line with the findings of the researches by Arai et al. (2013), Cortsen (2013), Ballouli \& Hutchinson (2012), Hasaan et al. (2016), Hasaan (2016), Hasaan et al. (2015) that the marketable lifestyle of the professional athlete has a positive and significant effect on fan loyalty $(15,19,26,28,29,31)$.

Development of a professional athlete's personal brand requires the presence of favorable individual and social behaviors for the athlete to be active in the marketing and sales of domestic products outside of the athlete's environment as an individual with a valid personal brand. Professional athletes also need to be accepted as a brand, with characteristics and values acceptable to the community. The results show that in addition to the factors that are known to contribute to the development of personal brand, experts believe that personal brand should also have rational and 
athletic values. A review of the models of Arai and Ko (2009), Shimp (2000), Clow et al. (2006), and Banyte et al. (2011) confirms this (32-35). Therefore, it can be said that the brand of professional athlete must also have rational and athletic characteristics and the prediction of such a result is not out of the question.

Arai et al. (2012) concluded that brand image perception varies across cultures. The results also showed interesting patterns regarding the components of human brand of the three countries. So, it turned out that some cultures, like the Japanese, value people as brands. For the Japanese and for the Japanese brand in the global marketplace, storytelling is seen as a key component of the human brand, as South Koreans believe competitiveness and symbolism are recognized as a component, and ultimately, Americans believe in the value of an elite athlete as a brand is based on attractiveness and fitness. Today they emphasize on the performance of an athlete in comparison to an athlete's face attractiveness and the use of athletes such as Lionel Messi and Cristiano Ronaldo confirms this. The outstanding performance of this world football star, far more than his apparent attractiveness, makes him worthy of his personal brand and his use in propaganda (36). Finally, it should be noted that, because of the novelty of the issue of personal branding in the field of professional athletes, this study sought to identify all the elements and micro factors influencing the athletes' personal brand. Therefore, it is suggested that athletes who intend to create and develop their personal brand should pay attention to their on-field and off-field features simultaneously.

\section{APPLICABLE REMARKS}

- Based on this study, it is suggested to managers and athletes that if they want to influence others and especially those who are interested in sports, they can develop his/her personal brand with the set of factors presented in this model.

- It is suggested that athletes have a strong presence in cultural, political and social activities and have clear ideas and positions on the new issues.

- It is suggested that future research will present a model of personal brand development for other human resources in sport such as coaches, teachers, referees, and so on.

- It is suggested that the research examines the barriers to athlete's personal brand development and their personal brand injuries.

\section{REFRENCES}

1. Malmi A. Political personal branding in social media under the European Parliamentary Elections 2014: Tampere University of Applied Sciences; 2014.

2. Kotler P, Armstrong G. Principles of marketing New York: Harlow; 2017.

3. Lair DJ, Sullivan K, Cheney G. Marketization and the Recasting of the Professional Self. Manage Commun Q. 2016;18(3):307-343. doi: 10.1177/0893318904270744

4. Rampersad HK. Authentic personal branding: A new blueprint for building and aligning a powerful leadership brand: IAP; 2009.

5. Castells M. Communication et pouvoir: OUP Oxford; 2013.

6. Shank MD, Lyberger MR. Sports marketing: A strategic perspective: Routledge; 1999.

7. Thomson M. Human Brands: Investigating Antecedents to Consumers' Strong Attachments to Celebrities. J Mark. 2018;70(3):104-119. doi: 10.1509/jmkg.70.3.104

8. Keller KL, Parameswaran M, Jacob I. Strategic brand management: Building, measuring, and managing brand equity: Pearson Education India; 2008.

9. Till BD. Managing Athlete Endorser Image: The Effect of Endorsed Product. Sport Mark Q. 2001;10(1):35-42.

10. Montoya $\mathrm{P}$, Vandehey T. The personal branding phenomenon: realize greater influence, explosive income growth and rapid career advancement by applying the branding techniques of Michael, Martha \& Oprah: Peter Montoya; 2002.

11. Jackson SJ, Andrews DL. Sport Stars: The Cultural Politics of Sporting Celebrity: Routledge; 2013.

12. Xiaohua H, Songling Y, editors. Research and Analysis on Operation Mode of a Personal Brand of Chinese Sports Star. 2010 International Conference on Management and Service Science; 2010.

13. Braunstein JR, Zhang JJ. Dimensions of athletic star power associated with Generation Y sports consumption. Int J Sport MarkSponsors. 2005;6(4):37-62. doi: 10.1108/ijsms-06-04-2005-b006

14. Sassenberg A-M, Verreynne M-L, Johnson Morgan M. A sport celebrity brand image: a conceptual model. Int J Org Behav. 2012;17(2):108-121. 
15. Cortsen K. Annika Sörenstam - a hybrid personal sports brand. Sport Bus Manage Int J. 2013;3(1):37-62. doi: $10.1108 / 20426781311316898$

16. Arai A, Ko YJ, Kaplanidou K. Athlete brand image: scale development and model test. Eur Sport Manage Q. 2013;13(4):383-403. doi: 10.1080/16184742.2013.811609

17. Gander M. Managing your personal brand. Policy Pract Hig Educ. 2014;18(3):99-102. doi: 10.1080/13603108.2014.913538

18. Green MR. The impact of social networks in the development of a personal sports brand. Sport Bus Manage Int J. 2016;6(3):274-294. doi: 10.1108/sbm-09-2015-0032

19. Hasaan A. Establishing athlete brand in criket: Fan's perception about foreign cricketers in pakistan super league (psl). Pamukkale J Sport Sci. 2016;7(3):23-39.

20. Figurska I. Personal branding as an element of employees' professional development. Hum Res. 2016;x(2):33-47.

21. Rangarajan D, Gelb BD, Vandaveer A. Strategic personal branding-And how it pays off. Bus Horiz. 2017;60(5):657-666. doi: 10.1016/j.bushor.2017.05.009

22. Erdoğmuş N, Esen E. Constructing the CEO Personal Brand: The Case of Four Pioneering CEOs in Turkey. Corp Reputat Rev. 2017;21(2):37-49. doi: 10.1057/s41299-017-0042-3

23. Hasaan A, Biscaia R, Ross S. Understanding athlete brand life cycle. Sport Soc. 2019:1-42. doi: 10.1080/17430437.2019.1624722

24. Dumont G, Ots M. Soc dynamic stakeholder relat person brand. Journal of Business Research. 2020;106:118-128. doi: 10.1016/j.jbusres.2019.09.013

25. Kelle U. " Emergence" vs." forcing" of empirical data? A crucial problem of" grounded theory" reconsidered. Hist Soc Res. 2007:133-156.

26. Hasaan A, Kerem K, Biscaia R, Agyemang K, editors. Athlete Brand: A Conceptual Framework to Understand Its Antecedents and Consequences. 2015 North American Society for Sport Management Conference; 2015: NASSM.

27. McFarland J. In the eye of the beholder. Nursing. 2002;32(6):46-47. doi: 10.1097/00152193-200206000-00042 http://ncbi.nlm.nih.gov/pubmed/12189983

28. Arai A, Ko YJ, Ross S. Branding athletes: Exploration and conceptualization of athlete brand image. Sport Manage Rev. 2014;17(2):97-106. doi: 10.1016/j.smr.2013.04.003

29. Hasaan A, Kerem K, Biscaia R, Agyemang KJ. Understanding the implications of athlete brand among fans. Technic Technol Educ Manage. 2016;11(1):68-81.

30. Tingchi Liu M, Brock JL. Selecting a female athlete endorser in China. Eur J Mark. 2011;45(7/8):1214-1235. doi: 10.1108/03090561111137688

31. Ballouli K, Hutchinson M. Branding the elite professional athlete through use of new media and technology: an interview with Ash De Walt. Int J Entrepreneur Ventur. 2012;4(1). doi: 10.1504/ijev.2012.044818

32. Arai A, Ko Y. Branding individual athletes: Development of a conceptual framework. 25 minute-oral presentation at the 24th North American Society for Sport Management Conference. Columbia SC United States. 2009.

33. Schimp T. Advertising, Promotion, and Supplemented Aspects of Integrated Marketing Communication. New York: Dryden Press; 2000.

34. Clow KE, James KE, Kranenburg KE, Berry CT. The relationship of the visual element of an advertisement to service quality expectations and source credibility. $J$ Serv Mark. 2006;20(6):404-411. doi: $10.1108 / 08876040610691293$

35. Banytė J, Stonkienė E, Piligrimienè Ž. Selecting celebrities in advertising: The case of Lithuanian sports celebrity in non sport product advertisement. Ekonomika vadyba. 2011(16):1215-1224.

36. Arai A, Ko Y, Chang Y, Chang K. Understanding Athlete Brand Image in Global Sport Markets: A Cross-National Study among Japan. South korea USA. 2012;20. 